Editorial

\title{
Letter from the Editors: Special Issue on "Effects of Coronavirus on International Business"
}

\author{
John Mezias, Editor ${ }^{1}$, William Newburry, Associate Editor ${ }^{1}$ \\ ${ }^{1}$ Florida International University, USA \\ Keywords: pandemic, government pandemic policy, global supply chains disruption, covid-19 and international business, covid-19 \\ $\underline{10.46697 / 001 c .18179}$
}

\section{AIB Insights}

In this article, AIB Insights' editors introduce their Special Issue focusing on effects of COVID-19 on international business policies and strategies. The seven articles published in this issue provide key insights for navigating international business during this pandemic.

As our world continues to struggle with the COVID-19 pandemic, many regions are facing a severe surge in new infections, hospitalizations, and deaths. Even initially encouraging vaccine trials and promises of quicker than normal regulatory approvals are tempered by the daunting logistics of distributing vaccines to potentially billions of people worldwide. The specter of additional economic shutdowns, continued travel bans, and the lack of global or regional plans for combating the virus demonstrate the increasing need for insights into navigating international business during such perilous times. AIB Insights is pleased to publish this Special Issue on "Effects of Coronavirus on International Business," which provides a platform for some key insights into dealing with this critical challenge.

We believe this to be the first peer-reviewed special issue published addressing this pandemic. As a more applied, practitioner focused outlet for international business insights, $A I B$ Insights is positioned to publish special issues relatively quickly. We received 41 submissions to this special issue, which is a testament to the importance of this topic and a record number for any issue of $A I B$ Insights. This issue is the first to utilize our recently formed Editorial Board, ${ }^{1}$ and we thank them for their willingness to serve and their contributions to shaping and developing the seven insightful articles in this issue, which were selected in a very competitive process. We are proud of these articles that provide applied insights stemming from how the pandemic is affecting a broad array of international business practices.

We start the issue with two articles with strong policymaker implications. First, the multidisciplinary team of Denise Dunlap, Roberto Santos, David McManus, Bryan Buchholz, Nathaniel Hafer, and Mary Ann Picard, representing Schools of Business, Medicine, and Engineering, examines potential benefits of a decentralized approach to clinical trials. Efforts to quickly develop safe and effective treatments for the virus have challenged normal procedures for conducting multi-country clinical trials. The authors develop a typology of four healthcare firm strategies based on two key industry trends impacting coronavirus vaccine development: decentralization and deglobalization of clinical trials. They then offer strategic lessons based on these four strategies.
Next, authors Jane Menzies and Matevz (Matt) Raskovic discuss how social resilience in Australia and New Zealand has proved helpful in combating the pandemic. Drawing on the cases of Australia and New Zealand, the authors propose a meta-capability social resilience approach to address unique policy challenges stemming from COVID-19. Specifically, the framework utilizes four types of capabilities (Anticipatory, Coping, Adaptive, and Transformative) which interact with a logic of social structuration and a distinction between proactive and reactive resilience.

Our third article, by Christine Côté, Saul Estrin, Klaus Meyer, and Daniel Shapiro, addresses how this pandemic can broaden the concept of "Distance" and suggests ways to expand teaching this critical concept accordingly. The authors argue that the impact of COVID-19 on international business activities highlights the dynamic nature of distance despite the static or slow-changing nature in which the construct is often taught in international business courses and conceptualized by researchers. Using the CAGE framework, they illustrate the implications of a dynamic conceptualization of distance by introducing likely effects of the pandemic based on travel barriers restricting the movement of people.

In the context of trade frictions and tensions among countries, Daniel Shapiro, Jing Li and Cai Mitsu Feng's case study examines the Liability of Origin (LOR) for a Chinese firm operating in the US. This article provides a detailed, applied example of how a firm addressed some issues identified in the prior Côté et al. article by examining the LOR that can result from conflicts between a company's home and host countries. Specifically, the authors examine the legitimacy challenges faced by Smithfield Foods (a Chineseowned meat processing company) in the US as tensions between China and the US increased during the COVID-19 crisis.

The final three articles investigate issues related to the geographic diversification of corporations, as seen through the lens of the pandemic. First, Luis Perez-Batres and Len Treviño examine benefits of integrating a real options perspective to managing global supply chains. They first noted that businesses and governments have difficulties reacting efficiently to black swan events like the current pandemic. They then propose a real options approach and advise firms 
to develop regional partnerships outside of densely populated areas to lessen supply chain disruptions due to uncertainties.

Next, Ofra Bazel-Shoham and Amir Shoham use the lens of this pandemic to question overseas production more broadly. Using economic arguments based on negative externalities, they argue that, from the perspective of a multinational's home country, international production can be suboptimal. This occurs because during times of crisis, such as the COVID-19 pandemic, moving production abroad can lead to insufficient home-country production, and excess production abroad as governments intervene and increase restrictions on transporting goods. This suboptimal outcome would be more likely for more essential products.

Finally, Kaitlyn DeGhetto highlights how this pandemic is challenging conventional wisdom related to international business and diversification. She notes how managing a global workforce during the pandemic resulted in additional challenges stemming from diverse policies, resources, and cultures of countries where a firm operates. Going forward, multinational executives should consider business continuity and strategic flexibility as important components of their investment decisions. Particularly in service-based industries, there will likely be a focus on countries with infrastructure that allows firms to leverage remote work.

The impacts of coronavirus on international business are highly complex, but we believe this special issue provides a strong starting point for understanding some of the impacts of COVID-19 on government policymakers, business decision making, and international business education. We hope these articles spur additional research examining the impact of COVID-19, and more broadly, global disruptive events in general.

We also look forward to the continuing development of AIB Insights. This, our first double-blind peer-reviewed issue, marks a significant milestone for the journal. As part of the AIB portfolio of journals, we will continue providing a publishing platform for Actionable International Business Insights.

Take care and stay safe! 